Authors' pre-publication version

Evans, A B, Allen-Collinson, J \& Williams, R K (2016 in press) Risky bodies, risky spaces, maternal 'instincts': swimming and motherhood. International Review for the Sociology of Sport.

Risky bodies, risky spaces, maternal 'instincts': swimming and motherhood

\author{
Adam B Evans, \\ University of Copenhagen, Denmark
}

Jacquelyn Allen-Collinson

University of Lincoln, UK

Rachel K Williams

University of Lincoln, UK

Corresponding author: Dr Adam B Evans, Department of Nutrition, Exercise and Sport (NEXS), University of Copenhagen, Copenhagen Denmark

Email: abe@nexs.ku.dk/ jallencollinson@lincoln.ac.uk 


\title{
Risky bodies, risky spaces, maternal 'instincts': swimming and motherhood
}

\begin{abstract}
Swimming and aquatic activity are fields in which gendered, embodied identities are brought to the fore, and the co-presence of other bodies can have a significant impact upon lived experiences. To date, however, there has been little research on sport and physical cultures that investigates how meanings associated with space impact upon women's embodied experiences of participating in swimming, specifically in the presence of their young children. Using semi-structured interviews and non-participant observations, this qualitative study employed a Foucauldian-feminist framework to explore self-perceptions and embodied experiences of aquatic activity amongst 20 women, who were swimming with children aged under 4. Results highlight that through 'felt' maternal responsibilities, the co-presence of babies' and children's bodies shifted women's intentionality away from the self towards their child. Mothers' embodied experiences were grounded in perceptions of space-specific 'maternal instincts' and focused upon disciplining their children's bodies in the lived-space of the swimming pool. Key findings cohere around mothers' felt concerns about hygiene, water temperature and safety, and elements of intercorporeality and 'somatic empathy'.
\end{abstract}

Key Words Swimming; Gender; Foucault; Embodiment; Motherhood; Intercorporeality 


\section{Introduction}

Physical-cultural practices such as swimming are both gendered and gendering (Henderson and Gibson, 2013), and wider socio-cultural values associated with gendered roles contour the way women and men experience sport (Abbas, 2004). The ways in which the female body is experienced, for example, are shaped by representations of body aesthetics, health and the interplay between multiple female roles including those of mothers (Azzarito, 2010; James, 2000). Feminist scholars argue that women and men can reproduce, resist or transcend dominant discourses of femininity within and through sport (Abbas, 2004; Allen-Collinson, 2011; Cronan and Scott, 2008). These have been shown to be grounded in the biomedicalization of women's bodies as the site of reproduction. It has been demonstrated, for example, how family roles often situate women in an 'ethic of care' as primary care-givers, which can in turn constrain women's choices, including in relation to sport and physical-cultural activities (Henderson and Gibson, 2013; Miller and Brown, 2005).

Aquatic leisure remains one of the most popular forms of physical activity in the United Kingdom, second only to walking in terms of participation, and tends to be undertaken primarily by women and children (Sport England, 2013). Moreover, swimming, as a sporting culture, has attracted attention from scholars who have outlined how gendered and gendering practices contour the experiences of participants. For example, Foucauldian feminists have analysed how normalizing practices regulate, discipline and contour women's bodies, including in competitive swimming (e.g., Lang, 2010, McMahon and Penney, 2013) and in recreational swimming (Evans and AllenCollinson, 2014; Lang 2010; Scott 2010). These studies have highlighted how the disciplinary gaze from others in the pool environment, including parents, coaches and other swimmers, serves to produce a culture of surveillance and disciplinary regimes in which the gendered body becomes a central focus. This culture of observation serves to normalize behaviours and regulate bodily 
practices such that they are routinely adhered to and reproduced by participants in a non-critical manner (McMahon and Penney, 2013). The swimming pool environment therefore has a panoptical quality in which ongoing surveillance, regulation and disciplinary techniques are employed by observers and participants alike in a manner which continually permeates the spaces of everyday life in an all-embracing, pervasive manner (McMahon and Penney, 2013; Scott, 2010). Amongst adolescent girls, for example, discomfort can be experienced when the female body is subjected to the 'male gaze' when wearing body-hugging clothing (James, 2000), but mothers have reported shifting their attention away from the self, toward regulating and disciplining their children's bodies during swimming (Evans and Allen-Collinson, 2014).

The enclosure of sports spaces contributes to the maintenance of such regulation, and it has been shown how performative regulation in the swimming pool contributes to a context-specific form of social organisation in which order and civility are recreated (Evans and Allen-Collinson, 2014; James, 2000; Lang, 2010; McMahon and Penney, 2013; Scott, 2010,). Indeed, it has been highlighted how within such a configuration of power relationships, swimming bodies begin to selfregulate such that they become the 'principal of their own subjection' (Foucault 1979: 172), even when, as when monitoring 'excess' weight in elite swimming, some of the practices are unhealthy and damaging to wellbeing (McMahon and Penney, 2013). Furthermore, studies have identified how embodied experiences of aquatic activity are influenced by expectations regarding hygiene, health and fitness (Evans and Allen-Collinson, 2014; Evans and Sleap, 2014), and that some aquatic activities, including aqua aerobics and 'parent-toddler' sessions, are often associated specifically with women's body projects (Evans and Sleap, 2012, 2013, 2014). These studies bring the centrality of the swimming body in gendered and gendering practices to the fore. By focusing upon swimming bodies, however, the manner in which the configuration of the pool morphology contributes to the production and reproduction of panoptical spaces recedes from analysis. 
Furthermore, less attention has been paid to the manner in which participants' sense of self can alter according to the co-presence of other participants within pool spaces. In short, by emphasizing the pervasiveness of a disembodied 'gaze,' the fleshy intercorporeality of other participants 'vanishes.' Such a lack of corporeal grounding implies the gaze is at the same time everywhere and nowhere. This is particularly problematic in the case of recreational swimming where bodies participate with others, including as part of a parent-child dyad. In such cases, the presence of other bodies in swimming spaces can influence participants' constructions of self and their negotiations of partitioned, enclosed swimming spaces in which bodies are surveyed and ranked on a continuous basis.

The socio-cultural production of women's roles has a spatial element, constructed in relation to other human bodies and material spaces. Embodied lives are intimately connected to others in a multiplicity of ways (Evans et al., 2011) such that the physical spaces of sport and exercise are coconstructed (Dyck and Dossa, 2007; Massey 2005: 10). Bodies are connected through and with material objects, spaces (Anderson and Tolia-Kelly, 2004; Allen-Collinson and Hockey, 2011) and emotions in the places we inhabit (Harrison and Anderson, 2012). Moreover, material things and spaces 'act back' and affect or effect us. It has been outlined how the discourses associated with such settings occur at the level of the encounter (Ahmed, 2000:145) and encapsulate the 'mobile coconstituencies of spaces, subjectivities and socio-spatial processes of power and inequality as embodied processes through which genders take place' (Thien and Del Casino, 2012: 1148). The gendered body is therefore experienced via intercorporeality, and enmeshed within a constant, ongoing process of connection with other human, non-human, past, present and future bodies (Evans et al., 2011). Concepts such as intersubjectivity and intercorporeality recognise this by challenging simplistic notions of bounded, independent embodied-subjects (Allen-Collinson and Hockey, 2016), but remain somewhat under-researched and under-analyzed in sport generally. We 
use the term intercorporeality here in the sense of the lived experience of corporeal 'we-ness' (Allen-Collinson, 2009), drawing upon Merleau-Ponty's (2001) notion of intercorporeité to describe how body-selves influence each other, for being embodied is never a private affair, but is mediated by interactions with other human and non-human bodies (Allen-Collinson and Hockey, 2016; Weiss 2013), as we consider below.

In this article, we focus upon the physical-cultural domain of non-competitive aquatic activity, including swimming, aqua aerobics and family-based aquatic-leisure sessions (see also Evans and Sleap, 2013; Evans and Allen-Collinson, 2014). Our research examined how post-partum mothers with children aged under-4 managed their children's bodies in swimming, through disciplining techniques of the self, conducted in swimming spaces and their surrounds. Having previously outlined how gender is experienced and contested by swimming mothers (Evans and Allen-Collinson, 2014), here, we focus specifically upon the spatial, sensory and intercorporeal elements of women's experiences, and situate our participants' subjective, embodied experiences within wider discourses of motherhood, utilizing a Foucauldian-feminist analytic framework.

\section{Foucauldian approaches in sport}

Foucault's approach centers upon the reconciliation of agency and structure through a sociohistorical lens (Markula, 2003). Within Foucault's conceptualization of society, subjects operate simultaneously in two terrains which intersect, or 'fold' at the level of the body. These terrains are referred to as the 'inside,' which refers to an individual's relationship with their subjective self, and the 'outside,' which refers to the networks of power and 'regimes of truth' located externally from the subject. In Foucauldian terms, the two terrains interact, or create a 'double', where the internalization of the outside by subjects is coupled with the notion that individual choices and actions act back. This creates an ongoing process of 'subjectivation' in which technologies of power 
located in the outside terrain and techniques of the self located on the inside terrain are closely intertwined (Foucault, 1982).

Within this post-structuralist model of society, Foucault (1979) conceptualised power as omnipresent, diffuse and flowing through society in a capillary-like fashion in an invisible and allembracing manner. Here, then, all bodies are constructed by and contour power relationships to some degree (Foucault, 1979), and can both produce and are subject to the operation of technologies of power. These technologies of power relate to the strategic production, reproduction and resistance of linguistic discourses, which are temporally contested and can co-exist in both complementary contradictory ways, and act to normalize or marginalize cultural practices (Cole et al., 2004). Power is thus unevenly distributed and can be both constructive and restrictive as discourses morph or change as bodies negotiate and make sense of their own social position (Lang, 2010; Pringle and Markula, 2005). This is because technologies of power interact with techniques of the self, as, according to Foucault, power has both constructive and restrictive capabilities because for power to exist, opportunities to resist also must exist (Pringle and Markula, 2005). This resistance takes place through the techniques of the self. Foucault (1988: 18) defines the techniques of the self as practices that:

permit individuals to effect by their own means or with the help of others a certain number of operations on their own bodies and souls, thoughts, conduct and way of being, so as to transform themselves in order to attain a certain state of happiness, purity, wisdom, perfection, or immortality.

Thus, within the techniques of the self, an individual can begin to reflexively recognize their own subjectivity and, potentially, resist or transform the outside terrain in a highly context-specific manner according to the ability of an individual to actively engage in techne, or practices which focus upon the self rather than upon the recreation or adherence to social laws (Markula, 2003). 
These techne include practices of ethical self-care, in which subjects engage in a code of ethics that is self-oriented rather than one which reproduces dominant discourses, and which leads to aesthetic self-stylization and critical self-awareness. Hence, the ability to think critically about one's social position enables a subject to question what is seemingly 'natural,' and to begin to create an identity of one's own. As Markula (2003: 102) outlines, 'through this interrogation of the limits of one's subjectivity, the possibility of transgression emerges and thus, the potential for creating new types of subjective experiences.' On the other hand, it is important to note that such opportunities can be limited, and not all subjects have the means, desire or resources with which to engage successfully in such techne.

Hence, a tension exists between disciplinary power enacted on the body through technologies of power, and power enacted by the body (Miller and McHoul, 1998). The body is therefore conceptualised as 'mindful' because of the operation of discourses at the level of the mind, which imbue bodies with meaning through language and techniques of surveillance, and which in turn place people's actions and intentions under scrutiny (Foucault, 1978). Indeed, Foucault considered power to have a panoptic quality that operates through techniques of surveillance. Using the example of Bentham's notional 'panoptical' prison (Foucault, 1979) in which a central tower is surrounded by a circle of cells which can be observed, but whose occupants cannot observe the contents of the tower, Foucault highlights how the threat of surveillance becomes omnipresent, creating self-regulation amongst those who feel under observation. Such surveillance also leads to the process of 'individuation', whereby individuals are identified and categorised by numbers, marks and signs, which are related to the establishment of norms. These not only regulate, but stimulate behaviors. As Foucault (1978: 57) highlights, people are encouraged to 'get undressed but be slim, good looking, tanned!' Surveillance is therefore disciplinary, and when internalized works to regulate actions, minds and bodies to the extent of 'docility' (Foucault, 1975). Power 
therefore creates 'docile bodies' that may be subjected, used, transformed and improved by technologies of power, and yet, because of the double, can be productive and transformative (Johns and Johns, 2000; Lang, 2010; Pringle and Markula, 2005). Moreover, the interplay of selfknowledge and discursive practices means that most individuals remain unaware of the network of power relations that constrain them (Barker-Ruchti and Tinning, 2010; Johns and Johns, 2000; Webb and Quennerstedt, 2010).

Networks of power relationships have a spatial element. Foucault theorized space less in territorial terms and more in terms of process and the enactment of power. For Foucault, territory is 'first of all a juridico-political one: the area controlled by a certain kind of power' (Foucault 1980: 68). The enactment of power has therefore a temporal, linguistic as well as spatial character. In illustrating this point, Foucault (1979) highlights how political and economic changes have taken place, predominantly through institutions, which relate to the exercise of power in the use of space. Spaces are partitioned, enclosed, subject to timetables and regulatory techniques which serve to inscribe them with specific meanings and regimes of truth. In turn, these regimes serve to regulate and discipline the bodies that exist within or traverse through them to the extent of docility. Furthermore, the way in which bodies act and are acted upon in space is dependent upon a number of processes, including: i) the art of distribution, or the distribution of bodies according to their mental, physiological and personal attributes, ii) control of activity, or the temporal, spatial control of the techniques of the self in which bodies engage, iii) the composition of forces, which relates to the organization of power relations within social groups, and iv) the organization of geneses, which relates to the increasingly linear regime of learning in social configurations which makes possible the control of activities (Barker-Ruchti and Tinning, 2010).

Foucauldian feminists have highlighted the complex, gendered dimensions within tensions contained in the double. In particular, they have highlighted how normalizing practices regulate, 
discipline and contour women's bodies to the extent of docility according to gendered discourses (Lang, 2010). Moreover, gendered discourses produce a multiplicity of femininities that operate with different intensities across temporal and spatial contexts, rendering the self unstable, disunited, fragile and subject to change (Pringle and Markula, 2005). Foucauldian approaches also highlight the multiplicity of embodied, conflicting and contested gendered identities which co-exist (Azzarito, 2010) and the ability of women to utilize power to advance different subject positions, as opposed to simply unilaterally being oppressed by patriarchal power (Johns and Johns, 2000; Markula, 2001; Pringle and Markula, 2005). This approach emphasizes how both men and women have social transformative potential as active agents who craft different ways of knowing themselves that can challenge, or reproduce, gendered domination (Barker-Ruchti and Tinning, 2010; Markula-Denison and Pringle, 2006; McMahon and Penney, 2011).

In aquatic activities, the art of distribution of bodies within and around a swimming pool creates a gendered context in which 'order' and 'civility' are maintained through the mutual scrutiny of near-naked bodies presented in asexual, socially constructed 'just a swimmer' roles. This social configuration is fragile, however, and vulnerable to challenge, disruption or threat and is maintained only through participants' adherence to reflexive body techniques and tacit disciplinary rules, including the 'de-sexualisation of encounters' (Scott, 2010). As noted earlier, this involves engaging in 'civil inattention' to near-naked bodies in the pool, which helps to maintain personal space. It also includes avoiding 'touch' by swimming in regulated patterns in a unidirectional manner, and avoiding conversation beyond the exchange of pleasantries (Scott, 2010). Embodied regulation can also be heightened by consciousness of the gendered gaze in the geography of the swimming pool, which often comprises viewing galleries, windows and shared spaces around lockers, showering facilities and changing room corridors (Evans and Allen-Collinson, 2014). Furthermore, Foucault (1995) discussed how 'body-object articulation' can result in the production, 
reproduction and resistance of power in spaces and through objects when they interact. In such a way contested spaces and objects can become associated with gendered discourses.

To date, little academic attention has been given to analysing intercorporeality in terms of the impact of co-present bodies upon regulatory practices within the spaces of aquatic activity, including within the liminal spaces in and around the pool and in the specific medium of the water. From a phenomenological perspective, however, Merleau-Ponty's (2001) emphasis on intercorporeality as a key element of our being-in-the-world is certainly germane to our analysis, particularly the notion that 'doing sport' or physical-cultural activities together is often accomplished by a form of 'intuitive' corporeal engagement with the world and with others (AllenCollinson, 2008; Allen-Collinson and Hockey, 2016) and by shared experiential and corporeal ways of knowing. We come to understand - although never completely or finally (Smith et al., 2009) - via shared 'somatic knowledge' (Allen-Collinson, 2011) - what other bodies are feeling, and we adjust our own actions in accordance with that understanding. So, for example, in swimming-together with their young children, not only do mothers see/feel 'goose pimples' on their child's skin, but they know experientially the feeling and significance of having goose pimples and of being cold and shivery. They may then subsequently act on the basis of this experiential knowledge to protect their child from the cold and seek to keep her/him warm.

The notion of 'liminal' space refers to zones of transition between social spaces. Liminal spaces exist 'betwixt and between' and are 'of' both, so that within liminal spaces the social norms of one space are transformed into those of a second, related space. In the swimming environment, such spaces include changing rooms, foot baths and other areas around the pool where participants make transitions - they 'become' swimmers on entry to the pool, and vice versa on their exit from the pool space (Evans and Allen-Collinson, 2014; Scott, 2010). This article reports key findings from a qualitative study that investigated mothers' perceptions of aquatic activity in the presence of their 
young children. We examine the manner in which the meanings associated with swimming spaces are understood, intersubjectively and inter-corporeally, by participants when in the presence of their children. We also examine how these socio-spatial meanings are contested according to gendered roles. Space/place is, we argue, implicit in Foucauldian approaches, but has previously been underexplored. Here, we seek to highlight the role of space/place in sociological analyses of sporting and physical-cultural activities. We next consider the methods employed in the study.

\section{Methods}

Data were collected by the full-time researcher, Rachel, via nine weeks of field observations, combined with 20 semi-structured interviews conducted with women aged 18-45, who had given birth within the previous four years. Initially, observational field notes were maintained over a nineweek period through the use of an observation sheet structured according to Foucault's (1978) four theoretical 'analytic tools:' the art of distribution, control of activity, composition of forces and the organisation of geneses (Barker-Ruchti and Tinning, 2010). All sessions took place on weekends between the hours of 9.00am and $6.30 \mathrm{pm}$. Rachel, a young woman of a similar age to many participants, attended a number of parent-toddler swimming sessions and also general leisure swimming sessions where parents and children were present. In an effort to not unduly influence participants in the research setting, she adopted behaviour and attire congruent with the latter (e.g. dressed in swimwear, took part in reading on poolside loungers and used the swimming facilities). As a woman researcher, she had access to certain areas of the pool, but not others, such as male changing areas.

Participants observed in swimming sessions were then opportunistically sampled and asked if they wished to take part in a semi-structured interview. All participants were women of a white- 
British ethnicity, which was reflective of the dominant ethnic group in the research setting. Eight participants had young children (aged under 3) present during interviews, but no older children were present on any occasion.

Rachel approached participants when they arrived at the swimming pool after changing, to ask if they would be willing to participate in the study, at which point informed consent was obtained. Participants were offered the choice of whether interviews should take place pre- or postswimming; approximately half chose each option. Participants were also given the choice of having their children accompany them in interviews. As most participants attended swimming with family members or others, only three mothers with particularly young children chose to bring these with them. Interviews lasted between 30 and 45 minutes. This approach allowed us to capture women's accounts of experiences and perceptions from directly within the context of the activity. With the permission of the pool manager, interviews took place in the staff office, helping create a comfortable atmosphere for participants to feel at ease. Rachel began each interview by asking women about their child/children, and it quickly became apparent that this approach set participants at ease, enhanced rapport and contributed to her credibility through the discussion of a 'meaningful' topic. Subsequent topics of inquiry focused entirely upon participants' experiences of swimming with their children while the latter were under-three, and included women's experiences of swimming, their preferred swimming activities, companions and schedules, their embodied experiences of swimming including with their young children, their perceptions of self, and sensory experiences of swimming.

The combination of semi-structured interviews and observational field notes generated rich data and produced a multi-dimensional account. Data were analyzed using Sparkes and Smith's (2013: 117-8) logical framework, including data immersion, reading and re-reading data carefully to identify and label themes in relation to research questions. Statements/themes were then grouped 
under codes, to identify consistencies and anomalous examples. Connections between themes were established by seeking patterns and explanations in the codes, and where connections existed, codes were grouped into higher order themes. Data were then cross-checked and related to theoretical concepts to help explain meanings. 'Contradictory' data were discussed within the research team and examined against the original transcript to ensure that all salient themes and categories were represented (see also Sparkes and Smith, 2013). A table was produced to highlight the structure of the analysis and hierarchical nature of the themes produced. Additionally, the research team completed detailed checks for resonance/meaningful coherence in the coded data (Tracy, 2010). Within these discussions, judgements of resonance and coherence were not considered static or immutable, and a relativist approach was taken to judging data quality as commensurate with Foucault's approach to the linguistic nature of meaning (Foucault and Gordon, 1980) in which the historical development of cultural 'knowledge' and 'rules' are embedded in linguistic form. Hence, by examining participants' delineation and expression of the conventional 'order' of things, we could begin to uncover what participants perceived to be the 'requirements' of conformity within the parent-child swimming culture, without reflecting a static, objective truth (Markula-Denison and Pringle, 2006).

In summary, the general dimensions and higher order themes formulated from the coding process included the construction of gendered, embodied techniques of the self in the spaces of aquatic activity and liminal spaces around the pool, together with parenting techniques, intercorporeality, discipline and the management of young vulnerable bodies. These themes are explored in the next section, where pseudonyms have been given to all participants.

\section{Results and Discussion}

Data analysis revealed a number of themes participants used to describe their experiences of swimming as mothers, cohering around three interlinked themes. First, participants rationalized 
their gendered roles as mothers and care-givers in the swimming pool space as 'natural.' Second, they outlined how perceptions of their gendered role influenced their embodied experiences of being an effective care-giver to their child, especially in traversing the risky, 'dirty' liminal spaces between the 'outside' world and the swimming pool. Third, interviewees described how in the more 'public' space of the swimming pool, they felt under surveillance regarding their parenting techniques and management of their young children's bodies. We begin by considering: 1) the gendered dimension of parent-baby swimming as a spatially 'maternal' activity, before examining 2) techniques of the self and the disciplining of children's bodies in liminal spaces, and then 3) within the pool space.

\section{Swimming spaces and the 'maternal'}

For our participants, aquatic activity was perceived as a predominantly female/feminine activity. In particular, interviewees reported that family-based swimming was associated with discourses which centred upon their role as maternal care-givers, partly because it was often scheduled at times when (male) partners were in paid work, and partly due to perceptions of discourses surrounding their own 'maternal instincts'. Although in the present study, the pool was ostensibly open to all, the production of 'swimming-together' caused participants to focus upon how they considered swimming spaces to be coded in a gendered manner (Foucault, 1979). Several participants outlined their embodied role of mother as care-giver was considered 'natural' in the aquatic environment, where they were 'safer' guardians of their babies, although the precise reasons for such feelings were difficult for them to identify:

Well, I just feel safer taking my son swimming. I think it's hard when you have a baby, erm... well to trust other people with your baby. I think it is a big thing, it is your job to look after your child and make sure nothing can hurt them and sometimes that's even the 
people around you like my husband that I do trust but I just feel better if my son is with me when swimming. I don't really know why (Lizzie, 30, mother of 1).

Participants' gendered assumptions based upon discourses of 'caring' extended to other women more generally, including, perhaps not surprisingly, their own mothers. This suggested gendered discourses were part of a more general organization of geneses relating to essentialist notions surrounding the social role of a mother as caregiver. Poppy, for instance, described her mother's 'maternal instinct':

She has a more maternal instinct, obviously my mother has been through it once before, she has had kids and she knows what to do (Poppy, 24, mother of 1).

Similarly, the notion that other women would somehow inherently 'would know what to do' with very young children was also applied to instructors, and almost all participants considered women to be more appropriate swimming instructors for young children than were men. As Ellie noted:

A woman [is a more appropriate instructor], I think that just because she may be a mother. I just have the perception that women are generally more motherly and they would be more capable looking after a child than a man (Ellie, 24, mother of 2).

Such discourses of maternal instinct can be difficult for women actively to resist (Miller, 2007), but also risk reducing women to 'biological' functions associated with reproduction and child-caring, rather than highlighting the social contexts that have produced such discourses (Hays, 1996). Interestingly, during the observations, at no time was a man seen teaching the younger children/babies how to swim, and during most of the observation period only women and children were present in the pool. Indeed, whilst most swimming services targeting our group of participants were labelled by the management in gender-neutral terms, they were often termed 'mother \& baby' swimming classes by participants themselves. On the rare occasion when a father did attend a 
swimming-class with his daughter, the art of distribution of bodies in the pool revealed him as isolated from the rest of the group. Participants subtly partitioned the pool space according to a gendered art of distribution (Foucault, 1979), and this father was situated at the back of a swimming class;a space was always maintained between him and other participants, serving to emphasize his 'alterity' within the composition of forces of the tacitly maternal swimming space (Observational field note, week 6).

Although interviewees generally indicated acceptance of 'natural' maternal roles, they also appeared to accept somewhat essentialist notions of male roles and bodies in the context of physical activity, commonly drawing on discourses of masculine protection, strength, bulk, and physical security. Lizzie, for example, explained how her husband's greater size rendered him better suited to a 'protective' role:

I was probably more comfortable when my husband held my baby in the water because I just felt that he was more protective of him. Erm... so yes, I felt fine when he was holding him and he is bigger and so if someone banged into him he is less likely to drop the baby and stuff (Lizzie, 30, mother of 1).

This created a degree of contradiction and tension; within the parent-child dyad, mothers considered they had the primary duty of care over children during swimming, but also perceived their husbands/male partners to be stronger 'protectors' against physical risks. Furthermore, it became clear that participants' perceptions of their maternal role shifted depending upon spatial context and the meanings associated with the lived, physical environment, including, for example, between the pool-space and changing rooms. We now consider these shifting perceptions, first vis-à-vis liminal spaces. 


\section{“Changing rooms are definitely the worst part!": liminal spaces}

Participants considered it an essential element of their role as a mother to ensure their child's safety in and around the pool space. Such spaces were considered to offer specific threats to their child's embodied integrity. Changing areas are often considered transitory spaces within which 'inside' and 'outside' routines, behaviours and also physical matter mix and blend, sometimes dangerously (Evans and Allen-Collinson, 2014; Evans and Sleap, 2014; Fusco, 2006). In these spaces, outdoor 'everyday' clothing is shed, and bodies are transformed into 'swimming' bodies through techniques of performative regulation and tacit etiquette. When emerging from the water and entering liminal zones in which individuals are ambiguously placed between the clothed and naked - 'civilised' and 'shameful' - it becomes harder, especially for very young children, to ignore the corporeality of others (Scott, 2010). In Goffman's (1972) terms, this can threaten the negotiated order of the pool, which usually includes respect for disciplinary regimes, respect for personal space, the desexualisation of encounters, and ritual 'civil inattention' to others. Our participants considered it essential to ensure their children adhered to these tacit rules. Interviewees reported surveying and disciplining their children's embodied behavior in order to prevent embarrassment. This included keeping them close and ensuring they did not crawl on the floor or on dirty surfaces. Moreover, the general acceptance of gendered discourses of the maternal role extended to encompass controlling their children's traverse of liminal areas such as the changing rooms, which were partitioned, enclosed areas whose accessibility was defined according to pool users' gender (Foucault, 1979). For participants in this study, this was first and foremost a space in which the employment of 'maternal' technologies of power in the regulation and disciplining of children's behaviour was considered most appropriate. Hence, many participants preferred to take their young children into the women's changing rooms rather than letting their husband/partner take them into the male changing rooms: 
Erm, I don't know why he would [take her in the male changing rooms] to be honest... Even if he ever went in with her by himself I would always take her out and change her. So I don't know how comfortable I would be with that actually probably not that happy. Because she is nearly two and she notices things like when you are getting changed she is becoming quite aware of physiological features and I think she would erm ... I think she would be a bit embarrassing really, for other people in there more than anything. She would talk about that sort of thing when she came out and again that would have a wider embarrassment context (Zara, 29, mother of 1).

According to participants, it was mothers' responsibility to survey and discipline their children's bodies whilst getting changed, regardless of the gender of the child. On no occasion during observations was a father seen taking a baby or young child into the male changing rooms. Interviewees rationalized that other women, as fellow 'maternal' bodies with similar concerns, might be less likely than men to find behavioural 'transgressions' by children problematic in changing rooms. Moreover, participants suggested that these practices were not dependent upon the gender of their child. Disciplining their children's bodies by ensuring conformity to the tacit rules of the changing-room area was associated with maternal care and also keeping proximity to their children's bodies. Mothers were keen to ensure that children respected the tacit rules of liminal and more 'back-stage' areas, in addition to the more 'public' space of the actual pool, by employing disciplinary techniques which produced a control of activity focused upon the act of transition between parent-child bodies to swimming bodies, within the parent-child dyad, rather than in relation to other pool users. Networks of surveillance, in this sense, became less outward-facing, and more focused upon the micro-physics of embodied self-stylization.

Central amongst women's concerns in these liminal areas, was the association of changing areas with 'matter-out-of-place', such as mud or 'dirt' brought into the changing rooms and 
deposited on floors and surfaces (Fusco, 2006). Here, corporeal detritus, such as hair, grease and waste is left, and sometimes exchanged, involuntarily, in a moist environment where water is also transferred via bodies from the pool and showers into the same areas. These 'abject' substances can present problems for bodies traversing such liminal spaces (Evans and Allen-Collinson, 2014). For example, newly-bared feet might come into contact with dirt and waste-matter on changing-room floors and surfaces. Interviewees highlighted that specific areas such as lavatories and gutters were strongly associated with poor hygiene, 'germs' and other materials perceived as health-threatening. Consequently, mothers (as carers) placed significant emphasis upon managing babies' bodies with regards to hygiene and safety in the changing-room environment, and were particularly concerned about standards of cleanliness:

I always think that the changing rooms can be a bit germy anyway. I have always thought that, so when you have a child your fears of that do multiply (Emma, 28 Year old mother of 1$)$.

Disciplinary techniques were considered important in preventing children's bodies from coming into contact with 'dirt', which was perceived to emanate from other bodies. This might be visible (such as one participant's recollections of finding used nappies in changing cubicles), or invisible. For example, Ellie worried that her children would get verrucae if their bare feet came into contact with changing-room floors, whilst Poppy described her concerns about invisible 'bacteria' thought to exist in gutters and toilet areas, and on moist surfaces of the changing rooms. Floors were considered dirty, even for standing on:

Yeah, there are never enough baby units to change your child on, especially the younger children and quite frankly I find some swimming pools dirty, like the floor and I 
wouldn't want to put them down on it. I put a towel on the floor so they don't have to stand on it (Charlotte, 36, mother of 6).

Furthermore, changing rooms were considered cold and uncomfortable locations in which transitions from/to clothed/unclothed state left young bodies in particular at risk of temperature change and discomfort:

Changing rooms are definitely the worst part of going swimming. When you get out of the pool and go into the changing rooms it is just freezing. Especially when you have got two children to help get dry, it is quite difficult. You are freezing yourself and you are trying to help both of them get dry and the cubicles are always really small and you have to look around for a non-dirty one (Stacey, 28, mother of 2).

Foucault (1978) has portrayed how modern forms of power, particularly through diverse techniques of discipline, control and normalize individuals to the extent of docility. Participants therefore considered it part of their maternal role actively to discipline their children's bodies in liminal spaces around the pool in order to maintain their safety (Evans and Allen-Collinson, 2014). These techniques of discipline were also enacted upon children's bodies in the pool itself, and took on a new dimension, being under the critical gaze of other parents, as we now portray.

\section{"I feel like they are looking at you and judging you": techniques of discipline in swimming}

Participants felt conscious of being monitored by the disciplinary gaze of other parents (especially mothers) within the swimming pool, and in a similar manner to that reported elsewhere (Lang, 2010; McMahon and Penney, 2013) several interviewees described how they felt surveyed and judged as mothers. In this case, however, the fluid and relatively informal nature of the activity meant that disciplinary techniques focused less upon the enforcement of disciplinary regimes, behaviours and schedules, and shifted instead to focus upon techniques of parenting. Such feelings 
were particularly acute because of the nature of the activity, in which young, almost naked bodies were subject to physical risks from the morphology and temperature of the pool and its surrounds, and from the water itself, and where the bodies of other participants impinged upon participants' experiences both physically and in terms of the transferral of 'germs' or fluids to their children through the medium of the water. Moreover, participants also felt responsible for the conduct of their children whilst in the pool, with its large, open spaces with extended lines of surveillance where sounds could be magnified. This seemed to emphasize any transgressive behaviour particularly if it affected other pool users and their children. Here, the norms and regimes associated with the pool and its perceived threats were contextually sphere-bound. Indeed, the poolspace itself placed the employment of maternal techniques in managing such risks under intense scrutiny from other pool-users, and this was particularly apparent when children 'transgressed' implicit norms or when familial 'presentation-of-self' was judged lacking:

Being judged by other people, other mums with children. You know you get in with your child and you feel like you are being watched and that everyone is watching you (Poppy, 24, mother of 1).

Sometimes yes [I feel like I am being watched] only due to the fact that I have six kids and some people may only have two. I can't imagine mine make any more noise than other children but because I have six...sometimes I think they look at me as to say, mad woman (Charlotte, 36, mother of 6).

Internalization of onlookers' gaze was also expressed in matters of bodily self-presentation and selfesteem specific to the swimming-pool context. Women's experiences of recent pregnancy were reported as an opportunity temporarily to 'step outside' the 'tyranny of slenderness' and the idealistic notion of the body beautiful (Markula et al., 2001). Nevertheless, whilst changes to 
weight, body size and shape were often accepted by women when actually pregnant, many considered this only a temporary situation:

Yeah, but I think probably most mums do, after having three babies it makes you a bit self-conscious of yourself in a public place wearing not very many clothes (Jan, 31, mother of 3$)$.

The context-dependency of disciplinary techniques became apparent, however, and several interviewees highlighted how the presence of their children changed their own self-perceptions:

Not [self-conscious] when I am with my child, all I worry about is him really. I used to be quite paranoid what I looked like before I had him though. I never used to go out without make-up and stuff. Now I don't feel like I even have time to put make-up on. So no, I don't care when I am with him, he splashes me anyway (Emily, 23, mother of 1).

This illustrates how the composition of forces (Foucault, 1978) present between mother and child/children altered women's engagement with certain disciplinary practices, which lost their salience in the post-partum period. Being a mother and having responsibility for a dependent child made some participants feel more comfortable in themselves and their bodies. Nevertheless, this did not represent participants' reflexive disengagement from dominant gendered discourses. Rather, the employment of disciplinary techniques shifted from self to children. Many subscribed to an 'intensive mothering' ideology where the needs of the child were viewed as of primary importance (Hays, 1996). Mothering practices are multifaceted, contested and in a constant process of negotiation, and a shifting, idealized model of mothering against which women are judged (Trussell and Shaw, 2012). The emphasis upon a child-centred, self-sacrificing, labor-intensive and emotionally absorbing model of motherhood can lead to feelings of guilt, tension and conflict, should mothers feel they fall short of the ideal (Hays, 1996). Interviewees reflected upon how they 
disciplined and regulated their children's behaviours in order to minimize risks, to avoid feeling cast as a 'bad mother' (Foucault, 1979):

I like to think that people think I am doing the right thing by her [daughter]... So people don't think I am being a bad mum and letting my child do that [i.e., going under water] and that sort of thing. I suppose usual mum anxieties (Lucy, 32, mother of 2).

Surveillance by other parents (especially mothers) has been shown to perpetuate standards of perfection (Henderson et al., 2010) and mothers situated themselves within this discourse at the nexus between external surveillance in 'public' spaces, and self-surveillance at an interpersonal level with a focus upon their child(ren) in more 'private' liminal spaces (see also, Trussell and Shaw, 2012; Evans and Allen-Collinson, 2014). For some participants such 'felt' surveillance created stress and anxiety:

When I did [swimming lessons with daughter] she was always the youngest. So [other children] would all be doing swimming and she would often cry and you're trying to like console her and you are just feeling like everyone is watching you and it is not very nice... I just find it really stressful because she would not enjoy [swimming] and it was quite hard. If she throws a tantrum in the pool then it was quite horrific... It is hard to support them when they are throwing a tantrum and things, so we got out (Lucy, 32, mother of 2).

Lucy's fear of her child's transgression of swimming-pool norms being harshly judged is perhaps not surprising, given idealized notions of mothering behaviours, which can generate great anxiety should these standards be transgressed (Henderson et al., 2010). For example, it was observed that a baby began crying after being submerged during a lesson, and his mother, increasingly flustered and subject to accusing looks from other parents, left abruptly after failing to quieten her child 
(observation, week 4). Furthermore, submerging their baby was highlighted as particularly problematic by many mothers:

I think sometimes other parents watch you especially when the little one goes under water...a lot of parents really hold onto their toddlers and don't let them do things like that. So you often get a look to say...oh, look what they are letting their child do, or is that safe? (Stacey, 28, mother of 2).

Although submersion in the water was adjudged to be 'difficult', most participants thought it a necessary part of building water-confidence, but nevertheless anxiety-generating:

Yes, I would [put child underwater], it would make me quite anxious actually putting my baby under the water but I know as a swimming teacher it is good for them to go under water. I would encourage putting them under water but I would be a little bit scared because you know that just every baby is going to come up crying... (Leanne, 37, mother of3).

Immersion of babies in the pool-water was considered problematic by participants because they perceived this water to threaten the corporeal integrity of their child by entering its body, posing the threat of illness. Water was perceived as a conduit for others' fluids, 'bugs' and germs. During one lesson, for example, it was observed that a baby was sick in the pool. Immediately, all parents (all mothers on that day) held their babies out of water to avoid contamination. Other threats from 'dirty' and 'smelly' pool-water were similarly feared, such as eye and ear infections, or general illness:

I think she got an ear infection from the water in the pool, the changing rooms are dirty so you can never tell how clean the water is. I don't put her down in the changing rooms but in the water everyone gets in it so you never know do you? (Helen, 26, mother of 1). 
I am concerned about cleanliness especially because everyone is in the same water and you don't know how clean people are! I know there are chemicals but hygiene is still a worry with a little child. I wouldn't want him to get poorly and sometimes the pool smells a bit (Lara, 31, mother of 1).

As a consequence, participants described engaging in disciplining techniques centred upon managing their children's bodies to protect them from potential pollutants.

Other perceptual risks focussed upon the pool environment and revealed heightened intercorporeality between mothers and babies, where the body is analysed as dynamically receptive and sensitive to social interactions with others in space (Trigg, 2013). Consequently, a transformation in bodily experience can be provoked by other bodies, such as when a mother is confronted by a visual or 'felt' change in her child in relation to thermoception and other sensations. This intercorporeal sensitivity and enaction (Allen-Collinson and Hockey, 2016) was evident in many participants' experiences:

Because they shiver and I feel cold in the water so they would probably feel the same, and when they are shivering you know that they are chilly (Jan, 31, mother of 3).

He cries after a while if he gets too cold, his lips go a bit blue but we always get out if that happens (Emily, 23, mother of 1).

When these mothers recognized corporeal indicators of children feeling cold, such acknowledgement was not as detached observers, but as intercorporeally-attuned subjects with shared experience of thermoception (see also Allen-Collinson and Owton, 2015). In a form of 'somatic empathy' interviewees also described how they sensed how cold their children were feeling. As Trigg (2013) asserts, the body has a potentiality enabling individuals to project themselves, via surveillance, beyond the limits of their own 'flesh'. Phenomenologists highlight the 
ways in which we can 'share' (to some degree) the felt experience of another in a world of shared inhabitance (Allen-Collinson, 2009). For participants, swimming-together involved a form of 'intuitive' corporeal engagement with their children, based on their own sedimented, corporeal ways of knowing and experience.

\section{Conclusions}

Above we have presented the key findings of a study of women's swimming with young children, analysed within a Foucauldian-feminist framework. Findings demonstrate the importance to mothers of managing the perceived risks to children posed by swimming. This included the need for self-regulation in the liminal spaces around the pool, and the more open, 'public' swimming pool itself. Interviewees tended to view the co-presence of other bodies, and their potential bodily detritus, as risky. In the art of distribution of bodies in swimming, bodily presences in the pool and discourses imprinted upon the both swimming and liminal spaces around the pool played a role in contouring the techniques of discipline women used to protect the vulnerable and 'fragile' bodies of their children. Participants described often feeling under surveillance, particularly in relation to their ability to fulfil an idealized image of mother-protector.

Our data showed that awareness of the disciplinary gaze was space-specific. In the open, almost cavernous spaces of the swimming pool, women's awareness of the disciplinary gaze of others expanded outward to incorporate multiple bodies, real or imagined, into their perceptions of constant, intrusive observation. This gaze, they felt, generated judgements regarding the effectiveness of their maternal techniques of discipline, enacted through the embodied mother-child dyad (see also Foucault, 1979). The 'production' of quiet, well-behaved children, who did not splash, excrete, or vomit in the pool, was considered vital in the 'public space' of the swimming pool, where parenting became a 'public act' (Trussell and Shaw, 2012). In liminal spaces around the 
pool, normative practice hinged upon the act of becoming a swimmer, whilst also negotiating the potentially threatening spaces that other bodies had traversed, and potentially 'contaminated'. Mothers sought to ensure their children were kept in close proximity, were safe and remained disciplined according to the tacit rules of the swimming pool. Surveillance and self-other regulation in the swimming context thus involved a distinct geo-spatial element which influenced the extent and directionality of perceived surveillance.

There are inevitable limitations to any generalization of our findings, given that the research covered a small sample of women of a similar age, socio-economic class, and ethnicity, in a specific UK region. Further studies with wider demographic coverage may furnish very different accounts of the experiential and intercorporeal elements of swimming and aquatic activity. Nevertheless, the findings of this study may have some implications for policy-makers and service-providers, in terms of the way in which swimming and aquatic activities are promoted and marketed to customers. Cleanliness and hygiene in swimming-spaces were of great importance to the mothers we studied, whilst the need to manage physical safety and water hazards was similarly highlighted as highly salient.

An element to date under-researched in research on swimming and aquatic activity, and which emerged strongly from our findings, is the role of intercorporeality, which is not specifically addressed in Foucault's work. It was clear that mothers were highly attuned to, and related empathically to, the moods, experiences and embodiment of their children within the lived space of the pool and surrounds. This relational process was portrayed by interviewees as quintessentially womanly-motherly. Indeed, analogous to Trussell and Shaw's (2012), findings, our participants felt that such close, embodied relationships could not be experienced and understood by men, even fathers. It also implies that the manner in which embodied experiences are understood is highly influenced by discourse and the spatially-specific, including surveillance of techniques of 
discipline, given that humans are in bodily relation with others in contextually-specific ways (AllenCollinson, 2008; Allen-Collinson and Hockey, 2016; Trigg, 2013). These contexts are influenced by the socio-cultural creation of meanings associated with space and place; in this case, discourses of maternal care, requiring techniques of discipline and the control of risks specific to swimmingspaces. This brings into sharp focus the need further to analyse a sense of space/place in sociological studies of gender, sport and physical cultures, as we attempt to deepen our understanding and analysis of gender in sport. 


\section{References}

Abbas A (2004) The embodiment of class, gender and age through leisure: A realist analysis of long distance running. Leisure Studies 23(2): 159-175.

Ahmed S (2000) Strange Encounters: Embodied Others in Post-coloniality. New York: Routledge.

Allen-Collinson J (2009) Sporting embodiment: Sports studies and the (continuing) promise of phenomenology. Qualitative Research in Sport and Exercise 1(3): 279-296.

Allen-Collinson J (2011) Intention and epochē in tension: Autophenomenography, bracketing and a novel approach to researching sporting embodiment. Qualitative Research in Sport, Exercise \& Health 3(1): 48-62.

Allen-Collinson J (2008) Running the routes together: Co-running and knowledge in action. Journal of Contemporary Ethnography 37(1): 38-61.

Allen-Collinson J and Hockey J (2011) Feeling the way: notes toward a haptic phenomenology of scuba diving and distance running. International Review for the Sociology of Sport 46(3): 330345.

Allen-Collinson J and Hockey J (2016 in press) Intercorporeal enaction and synchrony: The case of distance-running together. In Meyer $\mathrm{C}$ and van Wedelstaedt $\mathrm{U}$ (Eds), Intercorporeal and Interkinesthetic Enaction in Sports. Amsterdam: John Benjamins Publishing.

Allen-Collinson J and Owton H (2015) Intense embodiment: Senses of heat in women's running and boxing. Body \& Society 21(2): 245-268.

Anderson B and Tolia-Kelly D (2004) Matter(s) in social and cultural geography. Geoforum 35(6): 669-674.

Azzarito L (2010) Future girls, transcendent femininities and new pedagogies: Toward girls' hybrid bodies? Sport, Education and Society 15(3): 261-275. 
Barker-Ruchti N and Tinning R (2010) Foucault in leotards: Corporeal discipline in women's artistic gymnastics. Sociology of Sport Journal 27(3): 229-249.

Cole CL, Giardina MD and Andrews DL (2004) Michel Foucault: Studies of power and sport. In Giulianotti R (ed.) Sport and Modern Social Theorists. Basingstoke: Palgrave Macmillan, 207223.

Cronan MK and Scott D (2008) Triathlon and women's narratives of bodies and sport. Leisure Sciences 30(1): 17-34.

Dyck I and Dossa P (2007) Place, health and home: gender and migration in the constitution of healthy space. Health \& Place 13(3): 691-701.

Evans AB and Allen-Collinson J (2014) From 'just a swimmer' to a 'swimming mother': Women's embodied experiences of recreational aquatic activity with pre-school children. Leisure Studies, online early.

Evans AB and Sleap M (2012) 'You feel like people are looking at you and laughing': older adults' perceptions of aquatic physical activity. Journal of Aging Studies, 26 (4): 515-526.

Evans, AB and Sleap M (2013) 'Swim for Health': Program evaluation of a multi-agency aquatic activity intervention in the United Kingdom. International Journal of Aquatic Research and Education 7(1): 24-38.

Evans AB and Sleap M (2015) Older adults' lifelong embodied experiences of leisure time aquatic physical activity in the United Kingdom. Leisure Studies 34(3): 335-353.

Evans B, Colls R and Hörschelmann K (2011) 'Change4Life for your kids': Embodied collectives and public health pedagogy. Sport, Education and Society 16(3): 323-341.

Foucault M (1975) The Birth of the Clinic: An Archaeology of Medical Perception. New York: Vintage Books 
Foucault M (1978) The History of Sexuality, Volume 1: An Introduction (trans. R Hurley). New York: Vintage.

Foucault M (1979) Discipline and Punish: The Birth of the Prison. New York: Vintage.

Foucault M (1982) The subject and power. Critical inquiry 8(4): 777-795.

Foucault M and Gordon C (1980) Power/knowledge: Selected Interviews and Other Writings, 19721977. New York: Vintage.

Fusco C (2006) Spatializing the (im)proper subject: The geographies of abjection in sport and physical activity space. Journal of Sport \& Social Issues 30(1): 5-28.

Goffman E (1972) Relations in Public. Harmondsworth: Penguin.

Harrison P and Anderson B (2012) Taking-Place: Non-Representational Theories and Geography. London: Ashgate Publishing Ltd.

Hays S (1996) The Cultural Contradictions of Motherhood. New Haven, Connecticut: Yale University Press.

Henderson K and Gibson H (2013) An integrative review of women, gender, and leisure: Increasing complexities. Journal of Leisure Research 45(2): 115-135.

James K (2000) 'You can feel them looking at you': The experiences of adolescent girls at swimming pools. Journal of Leisure Research 32(2): 262-280.

Johns D and Johns J (2000) Surveillance, subjectivism and technologies of power. An analysis of the discursive practice of high-performance sport. International Review for the Sociology of Sport 35(2): 219-234.

Lang M (2010) Surveillance and conformity in competitive youth swimming. Sport, Education and Society 15(1): 19-37.

Markula P (2003) The technologies of the self: Sport, feminism, and Foucault. Sociology of Sport Journal 20(2): 87-107. 
Markula-Denison P and Pringle R (2006) Foucault, Sport and Exercise: Power, Knowledge and Transforming the Self. London: Routledge.

Markula P, Yiannakis A and Melnick M (2001) Firm but shapely, fit but sexy, strong but thin: The postmodern aerobicizing female bodies. Sociology of Sport Journal 12(4): 424-453.

Massey D (2005) For Space. London: Sage.

McMahon J and Penney D (2011) Empowering swimmers and their bodies in and through research. Qualitative Research in Sport, Exercise and Health 3(2): 130-151.

McMahon J A and Penney D (2013) (Self-)surveillance and (self-)regulation: Living by fat numbers within and beyond a sporting culture. Qualitative Research in Sport, Exercise and Health 5(2): $157-178$

Merleau-Ponty M (2001) Phenomenology of Perception (trans. C Smith). London: Routledge.

Miller T (2007) 'Is this what motherhood is all about?' Weaving experiences and discourse through transition to first-time motherhood. Gender \& Society 21(3): 337-358.

Miller YD and Brown WJ (2005) Determinants of active leisure for women with young children an 'ethic of care' prevails. Leisure Sciences 27(5): 405-420.

Pringle R and Markula P (2005) No pain is sane after all: A Foucauldian analysis of masculinities and men's experiences in rugby. Sociology of Sport Journal 22(4): 472-497.

Miller T and McHoul A (1998) Popular Culture and Everyday Life. London: Sage.

Scott S (2010) How to look good (nearly) naked: The performative regulation of the swimmer's body. Body \& Society 16(2): 143-168.

Shaw J (2012) The birth of the clinic and the advent of reproduction: Pregnancy, pathology and the medical gaze in modernity. Body \& Society 18(2): 110-138.

Shaw SM (2001) Conceptualizing resistance: Women's leisure as political practice. Journal of Leisure Research 33(2): 186-201. 
Smith B, Allen-Collinson J, Phoenix C, Brown D and Sparkes A (2009) Dialogue, monologue, and boundary crossing within research encounters: A performative narrative analysis. International Journal of Sport \& Exercise Psychology 7(3): 342-359.

Sparkes AC and Smith B (2013) Qualitative Research Methods in Sport, Exercise and Health: From process to product. Abingdon, Oxon: Routledge.

Sport England (2013) Active People Survey 7. Accessed 5 November, 2015. Available from: http://archive.sportengland.org/research/active people survey/active people survey 7.aspx

Thien D and Del Casino Jr V J (2012) (Un)Healthy 1 Men, masculinities, and the geographies of health. Annals of the Association of American Geographers 102(5): 1147-1156.

Tracy SJ (2010) Qualitative quality: Eight 'big-tent' criteria for excellent qualitative research. Qualitative inquiry 16(10): 837-851.

Trigg D (2013) The body of the other: Intercorporeality and the phenomenology of agoraphobia. Continental Philosophy Review 46(3): 413-429.

Trussell DE and Shaw SM (2012) Organized youth sport and parenting in public and private spaces. Leisure Sciences 34(5): 377-394.

Webb L and Quennerstedt M (2010). Risky bodies: health surveillance and teachers' embodiment of health. International Journal of Qualitative Studies in Education 23(7): 785-802. 